\title{
Chapter 5. Austronesian Prehistory in Southeast Asia: Homeland, Expansion and Transformation
}

\section{Peter Bellwood}

Austronesian origins are here presented as an example of a frequent phenomenon in world prehistory, whereby populations who develop agriculture in regions of primary agricultural origins are provided with essential economic advantages over surrounding hunter-gatherers. These advantages allow them to undertake the colonization of very large regions, and the records of such colonizations are visible in the archaeological and linguistic records. The pattern of Austronesian expansion, possible reasons for it, and some major factors influencing subsequent differentiation of Austronesian cultures are all discussed, commencing from about 4000 BC in southern China and Taiwan.

\section{Questions of Ultimate Homeland}

This paper will commence by focusing on the question of where the immediate ancestor of Proto-Austronesian was located, and when. Proto-Austronesian is the hypothesized linguistic entity, perhaps a single language or perhaps a dialect network (see Pawley and Ross, this volume), ancestral to all subsequent and existing Austronesian languages. But like all languages it also had an ancestor, prior to the budding of the Austronesian (henceforth An) family as a linguistic taxon with its own unique history.

An observation relevant for this question, one particularly intriguing in terms of its relevance for world prehistory, is that the general homeland regions of many of the major language families which have had long histories of association with agriculture seem to be geographically correlative with regions of primary (i.e. indigenously-generated) agricultural origins (Bellwood 1990b, 1991, in press b). In the Old World such language families include Indo-European, Elamo-Dravidian, Afro-Asiatic, Niger-Kordofanian, Nilo-Saharan, Sino-Tibetan, Austroasiatic, Thai-Kadai (or Daic of Ruhlen 1987) and Austronesian. The first two of these families, and possibly Afro-Asiatic, have arguable homelands in or closely adjacent to southwest Asia, the second two in northern sub-Saharan Africa, and the last three (with Sino-Tibetan being uncertain) in central and southern China. These three geographical regions are known from archaeological data to have witnessed major local developments of plant and animal domestication, in each case well before any such developments in intervening regions of the Old World (MacNeish 1992). Because of these widespread 
correlations between early centres of agriculture and major language family homelands (Renfrew 1992), one may posit a process whereby demographically-expanding agricultural populations moved outwards from primary agricultural homeland regions, perhaps slowly but certainly inexorably occupying lands previously occupied by foragers (as suggested for Europe by Ammerman and Cavalli-Sforza 1984; Renfrew 1987).

If one examines the geographical distributions of these major language families and the geography of diversity between and within them, one sees that areas of agricultural origin reveal both a larger-than-average number of different language families and high levels of internal language family diversity, as revealed by the close proximity of subgroups which have long histories of separation. This is true for the three areas listed, and also for the early agricultural homeland regions of central Mexico, the northern Andes of Peru and Ecuador, and New Guinea. Directly relevant for this paper, the Austronesian, Thai-Kadai, Hmong-Mien and Austroasiatic language families seem to have arisen by a process of dispersal out of subtropical southern China and northern Mainland Southeast Asia, a zone lying between the Yangzi and northern Thailand/Indochina, ${ }^{1}$ where the cultivation of rice and other crops developed widely between about 6000 and 3000 BC. Some of the Papuan language families of New Guinea are also associated with an early and primary centre of agriculture, although in this case the result seems to have been population maintenance and increase in situ rather than actual dispersal into new territories.

The Neolithic "revolutions" of China evidently occurred in two culturally-connected regions. The first, in the basin of the Yellow River, led to the domestication of foxtail and broomcorn millet by $6000 \mathrm{BC}$. The second, in the middle and lower Yangzi basin, led to the domestication of rice by about the same time (Yan 1991). However, although Chinese archaeologists tend to regard the Yellow and Yangzi basins as supporting unrelated Neolithic cultures, we perhaps need now to regard central and eastern China as one single centre for the early development of Asian monsoon agriculture.

Both rice and foxtail millet have been found in Chinese early Neolithic sites in storage pits and habitation layers, in quantities sufficiently large to suggest that they rapidly attained a major dietary importance. ${ }^{2}$ There is little doubt that they would have fuelled an increase in population numbers which was perhaps quite rapid, given the archaeological appearance of the oldest Neolithic cultures across huge areas of China by about 5000 BC (Chang 1986). One result of this would have been an outward expansion of those populations involved into areas which hitherto had been inhabited entirely by foragers.

By $5000 \mathrm{BC}$, settlements of rice cultivators were in existence down the eastern coastline of China to as far south as Guangdong, and by perhaps $4000 \mathrm{BC}$ in northern Vietnam and Thailand. In their archaeological remains are found 
assemblages of artefacts which leave no doubt about the overwhelming impact of the new lifestyle. For instance, the 7000-year-old village of pile dwellings at Hemudu, near the southern shore of Hangzhou Bay in Zhejiang Province, has yielded pottery, stone adzes, wooden and bone agricultural tools, evidence for carpentry and boatbuilding, paddles, spindle whorls for weaving, matting, rope, and large quantities of harvested rice. In addition, the site produced the bones of domesticated pigs, dogs, chickens and possibly domesticated cattle and water buffalo. Such a large village settlement and such a range of tools suggest a fundamental and drastic shift from the presumed mobile foraging lifestyle of the East Asian Late Palaeolithic. The inhabitants of Hemudu and other contemporary Chinese agricultural settlements lived during an episode of cultural evolution which was ultimately to have repercussions over the whole of temperate and tropical eastern Asia and the Pacific. One of these repercussions, albeit one which developed its first momentum a thousand kilometres or more south of Hemudu, was the ultimately-phenomenal expansion of the speakers of Austronesian languages.

\section{The Pattern of Austronesian Expansion}

It is necessary to return again to the linguistic evidence in order to plot the geographical axes of expansion of early An-speaking peoples. Beginning with the Pre-Austronesian level, a number of claims have been made for ancient genetic relationships between An and other Asian mainland language families (see footnote 1). Perhaps the best-known of these claims is the Austro-Tai hypothesis of Paul Benedict (1975; Reid 1984-5), which postulates that the Tai-Kadai and Austronesian language families once shared a common ancestral language or chain of languages spoken on the southern Chinese mainland. Benedict has suggested a number of important vocabulary reconstructions for this ancestral language, including terms for field, wet field (for rice or taro), garden, rice, sugarcane, cattle, water buffalo, axe, and canoe. The overlap between this list and that presented above for Hemudu and other coastal southern Chinese Neolithic sites needs little emphasis. One has to consider very seriously the possibility that the initial expansions of Austronesian and Tai-Kadai languages (and probably also Austroasiatic) began among Neolithic rice-cultivating communities in China south of the Yangzi. The archaeological record agrees very well and provides a date range for initial developments between 5000 and 4000 BC.

Moving beyond Austro- Tai into Austronesian proper, the reconstruction of linguistic prehistory which is most widely used today is that postulated by Robert Blust (1984-5). This is based on a "family tree" of subgroups and a hierarchy of proto-languages extending from Proto-Austronesian (PAn) forwards in time. Reduced to its essentials, Blust's reconstruction favours a geographical expansion beginning in Taiwan (the location of the oldest Austronesian 
languages, including PAn), then encompassing the Philippines, Borneo and Sulawesi, and finally bifurcating, one branch moving west to Java, Sumatra and Malaya, the other moving east into Oceania (see Darrell Tryon's more detailed summary in this volume).

A wealth of linguistic detail can be added to this framework, but here I will restrict myself to some implications of broad historical and cultural significance. During the linguistic stage before the break-up of PAn it would appear that some colonists with an agricultural economy moved across the Formosa Strait from the Chinese mainland to Taiwan (Bellwood 1984-5, 1992). Here developed the Initial Austronesian language(s), and after a few centuries some speakers of one of these languages made the first moves into Luzon and the Philippines. This movement led to the division of Austronesian into its two major subgroups, Formosan and Malayo-Polynesian (or Extra-Formosan). The reconstructed PAn vocabulary, which relates generally to this early Taiwan-Luzon phase, indicates an economy well suited to marginal tropical latitudes with cultivation of rice, millet, sugarcane, domestication of dogs and pigs, and the use of some kind of watercraft.

As a result of further colonizing movements through the Philippines into Borneo, Sulawesi and the Moluccas, the Malayo-Polynesian (MP) subgroup eventually separated into its several lower-order Western and Central-Eastern branches. The break-up of Central-Eastern MP probably occurred initially in the Moluccas, and Eastern MP contains all the Austronesian languages of the Pacific Islands apart from some in western Micronesia. The vocabulary of Proto-Malayo-Polynesian (PMP), a linguistic entity which might have been located somewhere in the Philippines, is of great interest because it contains a number of tropical economic indicators which were absent in the earlier and more northerly PAn stage. These include, according to Blust (1984-5), Colocasia taro, breadfruit, banana, yam, sago and coconut. Their presences may reflect a shift away from rice, a plant initially adapted to sub-tropical latitudes, towards a greater dependence on tubers and fruits in equatorial latitudes (Bellwood 1980a, 1985). The PMP vocabulary also has terms for pottery, sailing canoes and several components of substantial timber houses (Zorc 1994).

It may now be asked how the archaeological record relates to this reconstruction of the directions and cultural components of Austronesian expansion. Specific archaeological cultures cannot logically be equated with specific ancestral languages in prehistoric time. However, the appearance of certain technological and economic components of PAn and PMP can be searched for profitably in the archaeological record of the area now occupied by Austronesian speakers. As already indicated, it is a reasonable inference that both PAn and PMP represent agricultural societies who, amongst other things, grew rice, made pots, lived in well-made timber houses and kept domesticated 
pigs. As it happens, direct material evidence for all these items survives in the archaeological records of the islands of Southeast Asia, and all of them make an initial appearance in widespread excavated sites between about 4000 and 1500 BC. Furthermore, their appearances (especially pottery) show a time trend earliest in the northerly regions of China, Taiwan and Luzon, and progressively later as one moves southwards into equatorial Indonesia and western Oceania (Spriggs 1989). Given this seeming correlation between the linguistic and archaeological records (Bellwood 1985), we may hypothesize a direct association with the dispersal of the Austronesian language speakers, rather than dispersal of these cultural items by diffusion alone.

The Neolithic archaeological records in Taiwan began around 3000-4000 BC with archaeological assemblages of southern Chinese type, presumably carried initially by small groups of agricultural settlers across the Formosa Strait from Fujian (Tsang 1992). Characteristic artefacts of the oldest sites include cord-marked pottery, polished stone adzes and slate spear points. Other items such as slate-reaping knives and baked clay spindle whorls (for spinning thread for weaving) perhaps arrived a little later. By $3000 \mathrm{BC}$ in Taiwan there is evidence for rice and, from pollen records, for inland forest clearance for agriculture.

Between 2500 and 1500 BC related archaeological assemblages with plain or red-slipped pottery, rather than the older Taiwan cord-marked type, appeared in coastal and favourable inland regions of the Philippines, Sulawesi, northern Borneo, Halmahera, and (with domestic pigs) to as far southeast as Timor. No sites of this period have yet been reported from the large islands of western Indonesia, but research on pollen history in the highlands of western Java and Sumatra suggests that some fairly intensive forest clearance for agriculture was underway there by at least $2000 \mathrm{BC}$, and probably earlier (Flenley 1988). In the equatorial latitudes of Indonesia there may also have been a shift away from rice cultivation towards a much greater dependence on the tropical fruit and tuber crops listed above for the PMP vocabulary. No cereals were ever introduced into the Pacific Islands, with the exception of rice to the Marianas.

By 1500 BC, therefore, agricultural colonists had spread from Taiwan to the western borders of Melanesia. The continuing expansion through Melanesia into western Polynesia, represented by the Lapita culture, seems to have been even more rapid than preceding movements, perhaps because food producing (as opposed to purely foraging) Papuan-speaking populations were already occupying some coastal regions of the large islands of New Guinea, the Bismarcks and the Solomons. Finely decorated Lapita pottery has been found in coastal or offshore island sites from the Admiralties in the west to Samoa in the east, a distance of about 5000 kilometres (see following chapter). This Lapita expansion occurred between 1600 and $1000 \mathrm{BC}$ and to north and east of the Solomons it involved, for the first sustained period in Austronesian prehistory, the settlement 
of previously uninhabited islands. Between $1000 \mathrm{BC}$ and AD 1000 the settlement of these uninhabited regions continued onwards (Irwin 1992), ultimately to incorporate all the islands of Polynesia and Micronesia and, on the other side of the world, Madagascar (Map 1).

\section{Why did the expansion occur?}

The main points of the linguistic and archaeological records as they relate to early Austronesian dispersal, and possible reasons for it, can now be summarized. Austronesian-speaking agricultural colonists underwent a fairly continuous expansion (albeit divided into periods of relative stasis punctuated by rapid movement), over a period of about 4000 years, from the agricultural heartland region of southern China through many thousands of kilometres of coastline and across increasingly wide sea gaps eastwards into the Pacific. This expansion, which seems to have ignored island interiors in its early stages, met with stiff cultural resistance only in regions with prior histories of agriculture, these being restricted to mainland Southeast Asia and western Melanesia, the latter area being one where archaeology has indicated the existence of a prior and independent development of agriculture (Golson 1985; Golson and Gardner 1990).

The rate at which the early Austronesian colonization occurred must surely be one of the most rapid on record from the prehistoric agricultural world, although admittedly much of it was across sea rather than into large and absorbent land masses. It was probably not caused simply by an over-reliance on land-hungry shifting cultivation, an explanation which I have favoured in the past (Bellwood 1980b), but by a number of different stimuli. These include, not necessarily in order of significance:

1. continuous population growth based on an agricultural food supply, allowing a continuous generation-by-generation "budding-off" of new families into new terrain (cf. Ammerman and Cavalli-Sforza 1984 for a European model);

2. the inherent transportability and reproducibility of the agricultural economy to support colonizing propagules, especially on resource-poor small islands;

3. the presence of a deep and absorbent "frontier zone" available for colonization adjacent to the area of early Austronesian agricultural development, occupied purely by foraging populations (i.e. Taiwan and the Philippines in the early days of expansion), most of whom would presumably have shown little interest in adopting a systematic agricultural economy for themselves (Bellwood 1990b, 1991); 


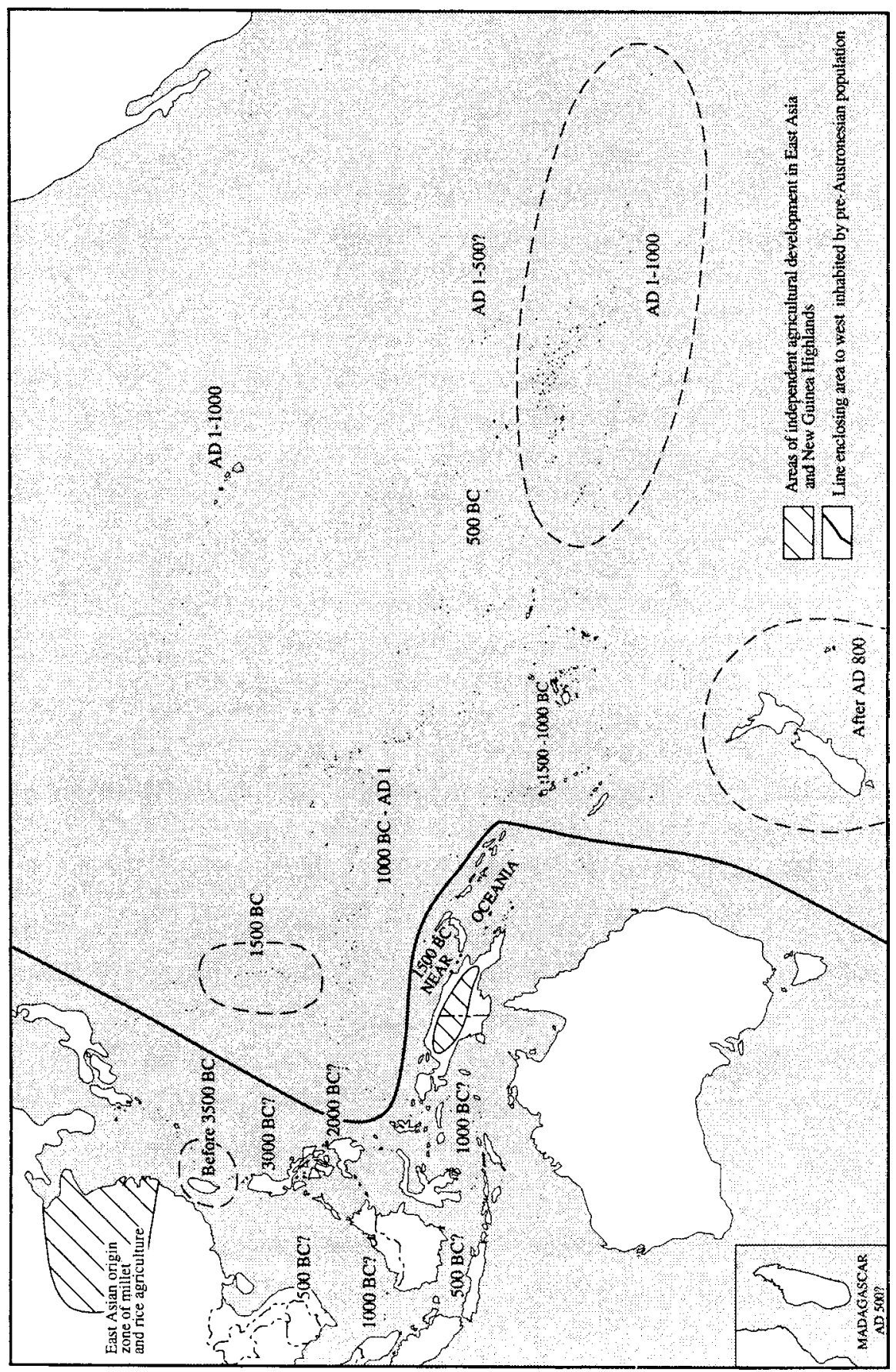

Map 1. Approximate dates for initial Austronesian colonization. 
4. a developing tradition of sailing-canoe construction and navigation (see Adrian Horridge in this volume);

5. a predilection for rapid coastal movement and exploration, probably to find the most favourable environments for cultivation and sheltered inshore fishing, and thus promoting a colonization pattern of wide-ranging settlement followed, often only centuries later, by territorial infilling;

6. a culturally-sanctioned desire to found new settlements in order to become a revered or even deified founder ancestor in the genealogies of future generations (presumably this evolved hand-in-hand with the colonization process itself - see Bellwood, in press a);

7. a desire to find new sources of raw materials for "prestige goods" exchange networks (Friedman 1981; Hayden 1983; Kirch 1988).

Not all of these stimuli were present before the process of Austronesian expansion began; those listed at (4) and (6) in particular surely evolved in part as a result of the process itself, as might (7) if it was of major significance as an agency of colonization (which I doubt; Bellwood in press a). However, it is my suspicion that the tap-root of the expansion process, a sine qua non, was the possession of a systematic agricultural economy capable of supporting continuous population growth.

The sceptic here may ask why, if agriculturally-induced population growth was so important, all early agricultural peoples did not simply expand in this way. I would reply that perhaps the majority of them did, and this becomes highly significant if one takes the view that early agriculture was an uncommon development in a primary form (i.e. as a result purely of local evolution from an indigenous foraging cultural base), restricted to only a very few specific environmental and floral/faunal regions of central Africa, southwestern Asia, China, New Guinea, Mesoamerica, the northern Andes and the Mississippi basin. As I have already noted, it is perhaps these early expansions, flourishing in a lightly populated, healthy and resource-rich world, ${ }^{3}$ which laid the bases for the distributions of many of the major language families of the Old World today.

\section{Transformations}

The early Austronesians began their ethnolinguistic career as subtropical coastal and riverine peoples with a Neolithic economy based on cereal and tuber cultivation and a set of domesticated animals. Their ethnographic descendants in island Southeast Asia managed to create for themselves a much wider range of subsistence economies, including rainforest foraging and collection-for-trade; sea nomadism (see Sather, this volume); varied forms of both irrigated and rainfed rice cultivation; shifting cultivation of cereals, fruits and tubers; and even palm exploitation (Fox 1977). Underlying causes for specific transformations can only be hypothesized, but such hypotheses will not proceed very far unless it is 
recognized that the early An colonists and their descendants must have been influenced by two kinds of landscape, the environmental and the human.

In terms of environmental factors, the Austronesian expansion would never have begun at all had its early participants been unable to cross the gaps of about $120 \mathrm{~km}$ between China and Taiwan, and between Taiwan and the Batan Islands. Zorc (1994) has recently pointed out how difficult it is to reconstruct terms for boats and navigation for Proto-Austronesian (as opposed to Proto-Malayo-Polynesian) and he suggests that much An seafaring terminology might have been lost in Taiwan owing to the heavy overlay of Chinese settlement in coastal regions. If so, the Proto-Austronesian vocabulary would once have contained more seafaring terms than it does now. Therefore, the obvious place to seek archaeological evidence for innovations in boat construction and navigation $^{4}$ may be amongst the hundreds of small islands which flank the coasts of Zhejiang and Fujian Provinces. To my knowledge these islands have produced few archaeological remains, apart from the fifth millennium BC pottery assemblage from the Fuguodun shellmound on Quemoy (Chang 1977; see also Chang 1992 for a recent update). However, if the Austronesians ever required a maritime "nursery", it might have been here.

A second environmental factor which affected the results of An expansion would have been the gradual shift from a seasonal sub-tropical climate into an ever-wet equatorial one as colonists moved southwards from Taiwan and the Philippines towards the Equator. Eventually, of course, the settlement of Java and southeastern Indonesia placed Austronesians back into a zone of markedly seasonal climate. But in the equatorial islands proper - Sumatra, Borneo, central Sulawesi, Halmahera - the prevailing climatic conditions probably promoted an economic reliance on tubers and fruits rather than the major cereals, rice and millet. I have argued this before in several publications (e.g. Bellwood 1980a, 1985) and see no reason to change my views, which do offer a convenient explanation as to why cereals should have been absent in Oceanic economies beyond western Micronesia; the northern New Guinea passageway into Oceania is completely equatorial.

Concerning the pre-existing human landscape of what is now western Austronesia an interesting and varied pattern can be reconstructed. Most of Island Southeast Asia was probably inhabited by foragers in pre-Austronesian times, and in the rainforests of Sundaland there probably would have been only very sparse settlement, mostly focused in coastal regions, many of which are now of course beneath sea level as a result of the postglacial ice melt (Bellwood 1990a). Denser populations doubtless existed in the more seasonal environments of Java, the Lesser Sundas and the central and northern Philippines, as witnessed in the Philippines by the existence of Agta foragers of a Melanesian-related physical type (albeit now An-speaking; Reid 1990) to the present. Indeed, in 
order to settle the Wallacean islands (Philippines, Sulawesi, Lesser Sundas, Moluccas), as also Australia and New Guinea, the original Pleistocene colonists must have had some degree of seafaring capacity, even if rudimentary, by at least 40,000 years ago. Did the Austronesians learn a number of seafaring skills from them, together with perhaps the uses of a number of equatorial crop plants such as breadfruit and coconut, which first appear in An linguistic history in the PMP vocabulary? I have already referred to Zorc's observation that rather little seafaring terminology is reconstructible for Proto-Austronesian. While it would be unwise to deny Proto-Austronesians the knowledge at least of canoes, it is worth remembering that much of the early expansion of the Austronesian-speaking peoples was through Wallacea, especially the Philippines and Sulawesi with their manifold satellite islands. It is amongst the more watery topography of Late Pleistocene Wallacea, rather than land-bridged Sundaland, that one might expect pre-Austronesian maritime traditions to have flourished and to have been transmitted to later arrivals (Irwin 1992).

Outside the islands of Southeast Asia the early Austronesians met with far stronger cultural resistance, both to the west and east. A different world again of course awaited colonists in the Pacific Islands beyond the Solomons - empty and inviting, with no attested pre-Austronesian populations at all (see following chapter).

The archaeological record now makes it clear that Neolithic populations occupied the whole region of Mainland Southeast Asia, including Peninsular Malaysia, by at least 2000 BC (Higham 1989; Bellwood 1993). The relevant archaeological affinities of all these cultures lie within the mainland region itself rather than across to the islands; perhaps it can be hypothesized that the majority of the agricultural populations of Thailand, Indochina and Peninsular Malaysia at this time spoke languages related most closely to the modern Austroasiatic family. In southern Vietnam the ancestors of the Austronesian Chamic-speaking peoples probably had to intrude into a landscape already peopled quite densely by such pre-existing cultivators. The Austronesian expansion into Peninsular Malaysia surely occurred long after the expansion of Austroasiatic cultivators (early speakers of Aslian languages) southwards from Thailand during the third millennium BC. Indeed, Austroasiatic-speaking cultivators might originally have colonized onwards quite rapidly into parts of Sumatra and western Borneo if one takes a broad view of the pollen evidence ${ }^{5}$ and some linguistic substratum hints (see Adelaar, this volume). The pre-existence of such agricultural populations in at least Malaya and Vietnam can explain why the mainland of Southeast Asia was only a region of small-scale prehistoric settlement by Austronesians, just as, under rather different cultural circumstances, was New Guinea. 
As on the mainland of Southeast Asia, so in New Guinea and western Melanesia the Austronesian colonists also met a major level of resistance biological, cultural and linguistic. The existence of primary agricultural development in New Guinea is no longer in doubt, even if it is unclear where it was focused (highlands or coasts?) and exactly how the participating economies functioned (Golson and Gardner 1990). Cultivation of plants, especially taro, is likely, but many coastal populations might have lifted their population densities to outsider-resistant levels by other forms of tree exploitation (sago and Canarium) or exchange of foodstuffs. Many of these peoples, like their Wallacean cousins, also knew how to cross sea, as witnessed by the Late Pleistocene discovery and distribution of New Britain obsidian (Allen et al. 1989). However, their seafaring skills were perhaps more limited than those of the later Austronesian settlers who, at about $1000 \mathrm{BC}$, were able to colonize far into western Polynesia and to trade Talasea obsidian from New Britain across a distance of 6500 kilometres from northern Borneo in the west to Fiji in the east (Bellwood 1989). This probably makes Talasea obsidian the furthest-distributed commodity of the whole Neolithic world.

\section{Some Final Generalizations}

Perhaps I may finally sketch, in brief, some of the major transformations which I believe prehistoric Austronesian societies underwent in Island Southeast Asia between about $4000 \mathrm{BC}$ and $\mathrm{AD} 1$.

1. 4000-3500 BC; Initial Austronesian expansion to Taiwan; settled cereal and tuber agriculture, limited seafaring.

2. $3000 \mathrm{BC}$; Proto-Austronesian expansion to the northern Philippines; improvement of seafaring technology, stylistic shift from cord-marked to plain or red-slipped pottery.

3. Late third and second millennia BC; Proto-Malayo-Polynesian dispersal from the southern Philippines to Borneo, Sulawesi and the Moluccas; equatorial enhancement of fruit and tuber production vis-à -vis cereals, except in more southerly and climatically-seasonal islands such as Java where rice has presumably always maintained its pre-eminence. One development of great interest which might have occurred about this time might have been the beginnings of forager adaptations to the rainforests of Borneo and Sumatra (see Sather, this volume).

4. Second/first millennia BC? Beginnings of mobile maritime (proto-sea nomad?) adaptations around the Sulu and Sulawesi Seas (cf. Bellwood 1989 for a maritime economy with long-distance exchange at Bukit Tengkorak, Sabah, around $1000 \mathrm{BC}$ ), and possibly elsewhere. These, in turn, might have laid some of the seafaring groundwork for:

5. Middle and late second millennium BC; Lapita colonization of Remote Oceania to as far as Tonga and Samoa. Seafaring skills were here developed 
further amidst an ever-expanding vista of uninhabited islands, but with few opportunities to settle on large western Melanesian islands (especially New Guinea) already inhabited by Papuan-speaking peoples.

6. Second/first millennia BC? Austronesian settlement in Vietnam and Malaya, in both regions in competition with pre-existing agriculturalists.

7. $500 \mathrm{BC}$ and after. Introduction of bronze and iron metallurgy into Island Southeast Asia. Dong Son drums were also traded from Vietnam into the Sunda islands, extending from Sumatra to the southern Moluccas.

Perhaps the metallurgical introductions listed last above were no more than side effects of something much greater; the incorporation of parts of Island Southeast Asia into a network of Old World trade stretching from the Mediterranean to eastern Indonesia. Indian pottery of c.200 BC to AD 200 has now been unearthed in Java and Bali (Ardika and Bellwood 1991), and at the same time the archaeological record reveals a hitherto-unprecedented level of similarity in local pottery design and manufacture across a huge region which includes coastal regions of the Sunda islands, Borneo, Sulawesi and the Philippines. It is possible that a great deal of linguistic assimilation of prior diversity occurred from this time onwards, for instance by the Malayic languages (especially Old Malay itself), Javanese and perhaps other languages or subgroups (cf. Blust 1991 for the possibility of some kind of linguistic levelling in the Philippines). By AD 500 the Western Austronesian area was perhaps a zone of continuously-flourishing inter-island travel and trade, with the odd proviso that Taiwan, where so many crucial developments had once occurred, was now divorced into an almost total isolation from the rest of Island Southeast Asia (Meacham 1984-5). Such are the enigmas of history.

\section{References}

Allen, J., C. Gosden and J.P. White

1989 Human Pleistocene adaptations in the tropical island Pacific. Antiquity 63:548-560.

Ammerman, A.J. and L.L. Cavalli-Sforza

1984 The neolithic transition and the genetics of populations in Europe. Princeton: Princeton University Press.

Ardika, I.W. and P. Bellwood

1991 Sembiran: the beginnings of Indian contact with Bali. Antiquity 65:221232.

Ballard, W.L

1981 Aspects of the linguistic history of south China. Asian Perspectives 24(2):163-186. 
Bayard, D.

1975 North China, South China, Southeast Asia, or simply "Far East". Journal of the Hong Kong Archaeological Society 6:71-79.

Bellwood, P.S.

1980a Plants, climate and people: the early horticultural prehistory of Austronesia. In J.J. Fox (ed.) Indonesia, the making of a culture, pp.57-74. Canberra: Research School of Pacific Studies, The Australian National University.

1980b The peopling of the Pacific. Scientific American 243(5):74-85.

1984-5 A hypothesis for Austronesian origins. Asian Perspectives 26(1):107117.

1985 Prehistory of the Indo-Malaysian Archipelago. Sydney: Academic Press.

1989 Archaeological investigations at Bukit Tengkorak and Segarong, southeastern Sabah. Bulletin of the Indo-Pacific Prehistory Association 9:122162 .

1990a From late Pleistocene to early Holocene in Sundaland. In C. Gamble and O. Soffer (eds) The world at 18,000 BP, Vol. 2, Low latitudes, pp.255263. London: Unwin Hyman.

1990b Foraging towards farming. Review of Archaeology 11(2):14-34.

1991 The Austronesian dispersal and the origins of languages. Scientific American 265(1):88-93.

1992 Southeast Asia before history. Chapter 1 in N. Tarling (ed.) The Cambridge history of Southeast Asia. Cambridge: Cambridge University Press.

1993 Cultural and biological differentiation in Peninsular Malaysia: the last 10,000 years. Asian Perspectives 32:37-60.

in press a Hierarchy, founder ideology and the Austronesian expansion. In J.J. Fox and C. Sather (eds) Origin, ancestry and alliance. Canberra: Department of Anthropology and Comparative Austronesian Project, Research School of Pacific and Asian Studies, The Australian National University.

in press b Prehistoric cultural explanations for widespread language families.

In P. McConvell and N. Evans (eds) Understanding ancient Australia: perspectives in archaeology and linguistics. Oxford: Melbourne University Press.

Benedict, P.K.

1975 Austro-Thai language and culture. New Haven: Human Relations Area Files Press. 
1976 Austro-Thai and Austro-Asiatic. In P.L. Jenner et al. (eds) Austroasiatic Studies, pp.1-36. Honolulu: University of Hawaii Press.

Blust, R.A.

1984-5 The Austronesian homeland: a linguistic perspective. Asian Perspectives 26(1):45-68.

1991 The greater Philippines hypothesis. Oceanic Linguistics 30(2):73-129.

Chang, K.C.

1977 A new prehistoric ceramic style in the southeastern coastal area of China. Asian Perspectives 20:179-182.

1986 The archaeology of ancient China (4th edition). New Haven: Yale University Press.

1992 Taiwan Strait archaeology and Protoaustronesian. Paper presented to International symposium on Austronesian studies relating to Taiwan, Academia Sinica, Taipei, December 1992.

Diffloth, G.

1979 Aslian languages and Southeast Asian prehistory. Federation Museums Journal 24:3-18.

Flenley, J.R.

1988 Palynological evidence for land use changes in South-East Asia. Journal of Biogeography 15:185-197.

Fox, J.J.

1977 Harvest of the palm. Cambridge, Mass.: Harvard University Press.

Friedman, J.

1981 Notes on structure and history in Oceania. Folk 23:275-295.

Golson, J.

1985 Agricultural origins in Southeast Asia: a view from the east. In V.N. Misra and P. Bellwood (eds) Recent advances in Indo-Pacific prehistory, pp.307-314. New Delhi: Oxford and IBH.

Golson. J. and D.S. Gardner

1990 Agriculture and sociopolitical organization in New Guinea Highlands prehistory. Annual Review of Anthropology 19:395-417.

Hayden, B.

1983 Social characteristics of early Austronesian colonizers. Bulletin of the Indo-Pacific Prehistory Association 4:123-134.

Higham, C. 
1989 The archaeology of mainland Southeast Asia. Cambridge: Cambridge University Press.

Irwin, G.

1992 The prehistoric exploration and colonization of the Pacific. Cambridge: Cambridge University Press.

Kirch, P.V.

1988 Long-distance exchange and island colonization: the Lapita case. Norwegian Archaeological Review 21:103-117.

MacNeish, R.

1992 The origins of agriculture and settled life. Norman: University of Oklahoma Press.

Meacham, W.

1984-5 On the improbability of Austronesian origins in South China. Asian Perspectives 26(1):89-106.

Norman, J. and T-L. Mei

1976 The Austroasiatics in ancient south China: some lexical evidence. Monumenta Serica 32:274-301.

Renfrew, C.

1987 Archaeology and language. London: Jonathan Cape.

1992 Archaeology, genetics and linguistic diversity. Man 27:445-478.

Reid, L.R.

1984-5 Benedict's Austro-Tai hypothesis: an evaluation. Asian Perspectives 26(1):19-34.

1990 The search for original Negrito: Negrito languages as creolized Austronesian. Paper given at 14th IPPA Congress, Yogyakarta, August 1990.

Ruhlen, M.

1987 A guide to the world's languages. Volume 1: Classification. California: Stanford University Press.

Spriggs, M.

1989 The dating of the island Southeast Asian Neolithic. Antiquity 63:587612 .

Tsang Cheng-hwa

1992 Archaeology of the P'eng-hu Islands. Taipei: Institute of History and Philology, Academia Sinica, Special Publication 95.

Yan Wenming 
1991 China's earliest rice agriculture remains. Bulletin of the Indo-Pacific Prehistory Association 10:118-126.

1993 The origins of agriculture and animal husbandry in China. In C.M. Aikens and Song Nai Rhee (eds) Pacific Northeast Asia in prehistory, pp.113-123. Pullman: Washington State University Press.

Zorc, R.D.P.

1994 Austronesian culture history through reconstructed vocabulary (an overview). In A. Pawley and M. Ross (eds) Austronesian terminologies: continuity and change, pp.541-594. Pacific Linguistics Series C No. 127. Canberra: Department of Linguistics, Research School of Pacific and Asian Studies, The Australian National University.

\section{Notes}

${ }^{1}$ While no comparative linguists appear to have addressed themselves specifically to an elucidation of this point, it does seem to me to be inherently likely if one accepts the opinions of, inter alia, Benedict (1975, 1976), Ballard (1981), Bayard (1975), Diffloth (1979) and Norman and Mei (1976). At a conference on Asia Mainland/Austronesian Connections, held at the University of Hawaii in May 1993, differing opinions were presented linking Austronesian genetically with Thai-Kadai, Austroasiatic and Sino-Tibetan. Although such opinions provoke much lively linguistic debate, owing to the unavoidable ambiguity of any claimed evidence at such great time depth, my own suspicion is that the ancestors of all these four language families might have been geographically contiguous early in the centuries of agricultural development in China, and that they should therefore share some degree of remote genetic relationship, or at least connections through early borrowing.

${ }^{2}$ For instance, Yan Wenming (1993) has suggested that the site of Cishan in Hebei (c.6000 BC) contained sufficient pit storage space for 100 tonnes of foxtail millet, and that Hemudu in Zhejiang (c.5000 BC) contained waterlogged rice remains equivalent to a yield of 120 tonnes of fresh grain.

3 Agricultural production and resultant demographic crowding might have lowered human health standards in the long run. But the first agriculturalists to develop systematic food production should have enjoyed high levels of health and fertility, such that local groups might have increased their numbers at similarly rapid rates to agricultural colonists in recent centuries in Australia and the USA. I have never been convinced that European so-called "colonial" experiences were totally unique to the past two centuries.

4 Such evidence would be unlikely to extend to actual boats or canoe parts, except under waterlogged conditions. However, evidence of frequent mainland-island contact could be gleaned from data on pottery and stone tool transport and on fishing methods (bones of offshore fish, for instance, might suggest the use of canoes). See Tsang (1992) for evidence of early contacts between Fujian, the P'eng-hu (Pescadores) Islands and Taiwan.

5 Flenley (1988) posits some degree of pre-4000 BP forest clearance in the Sumatran Highlands. 